\title{
The cell wall galactomannan antigen from Malassezia furfur and Malassezia pachydermatis contains $\beta$-1,6-linked linear galactofuranosyl residues and its detection has diagnostic potential
}

\author{
Correspondence \\ Nobuyuki Shibata \\ nshibata@tohoku-pharm.ac.jp
}

Received 12 April 2009

Accepted 15 April 2009

\author{
Nobuyuki Shibata, Tomomi Saitoh, Yukari Tadokoro and Yoshio Okawa
}

\author{
Department of Infection and Host Defense, Tohoku Pharmaceutical University, 4-4-1 \\ Komatsushima, Aoba-ku, Sendai, Miyagi 981-8558, Japan
}

\section{INTRODUCTION}

Members of the yeast genus Malassezia are important pathogens related to catheter-related fungaemia in premature neonates and other patients who are receiving parenteral nutrition supplemented with lipid emulsions (Dankner et al., 1987; Devlin, 2006). Most Malassezia species, including Malassezia furfur, require a lipid for growth. Therefore, the administration of lipid infusions through a catheter is a risk factor for Malassezia sepsis (Marcon \& Powell, 1992). A single non-lipid-dependent species, Malassezia pachydermatis, has been isolated from animals, including dogs, more frequently than from humans (Guillot \& Bond, 1999). The incidence of otitis externa in dogs, caused by M. pachydermatis, is reported to be closely related to ear shape, breed, and lipids in the auditory canal (Guillot \& Bond, 1999). M. pachydermatis has also been implicated in nosocomial systemic infections

Abbreviations: ABEE, $p$-aminobenzoic acid ethyl ester; DEPT, distortionless enhancement by polarization transfer; Galf, galactofuranose; HMBC, heteronuclear multiple bond coherence spectroscopy; HSOC, heteronuclear single quantum coherence spectroscopy; Man, mannopyranose; NOESY, nuclear Overhauser enhancement spectroscopy; TFA, trifluoroacetic acid; TOCSY, total correlation spectroscopy.
(Larocco et al., 1988; Welbel et al., 1994). Malassezia species are part of the normal cutaneous microflora of homoiothermic animals. However, certain conditions, such as high relative humidity, greasy skin, corticosteroid treatment and immunodeficiency, can allow these yeasts to become pathogenic and cause skin diseases, such as pityriasis versicolor, Malassezia folliculitis and seborrhoeic dermatitis (Ashbee \& Evans, 2002; Faergemann, 2002). Malassezia species are also regarded as exacerbating factors in atopic dermatitis and psoriasis. The genus Malassezia has been classified into eleven species based on molecular biological analysis of the nuclear rDNA/RNA (Hirai et al., 2004; Sugita et al., 2004).

The cell wall of pathogenic fungi represents the initial point of interaction between the host and the pathogen. Cell wall composition and structure are strongly associated with the adherence to and penetration into tissues. The dynamic nature of the fungal cell wall allows the yeast to overcome host defences. The cell wall of fungi is composed of a tight matrix of polysaccharides and proteins. In the case of Candida albicans, the representative opportunistic yeast pathogen, the cell wall polysaccharide is composed of mannan, $\beta$-glucan and chitin. Proteins within the cell wall 
matrix are cross-linked to the cell wall polysaccharides. Mannan, the outermost layer component of the wall, behaves as a potent antigen and has been utilized as the target for the diagnosis of invasive candidiasis. It has been shown that mannosyltransferase deletion mutants of $C$. albicans have reduced pathogenicity (Bai et al., 2006; Bates et al., 2006; Lengeler et al., 2008). Furthermore, it is known that there are many mannose recognition molecules, such as the mannose receptor, dectin-2, the dendritic-cellspecific intercellular adhesion molecule-3 (ICAM-3)-grabbing non-integrin (DC-SIGN), galectin-3 and mannanbinding protein (Willment \& Brown, 2008). These molecules are known to induce innate immune responses to microbial infection. However, there has been a limited number of studies of the antigenicity of the cell wall polysaccharide of the genus Malassezia. The cross-reactivity of $\operatorname{IgE}$ and $\operatorname{IgG}$ antibodies in atopic dermatitis patients to the mannans of M. furfur, C. albicans and Saccharomyces cerevisiae has been reported (Doekes \& van Ieperen-van Dijk, 1993; Lintu et al., 1999; Kosonen et al., 2005). Although the structure of the mannans of the C. albicans serotype A and B strains (Shibata et al., 1995, 2007) has been determined, there appear to be no reports of the structure of the cell wall polysaccharide of the genus Malassezia. The genus Malassezia has a lipophilic nature, and the surface of the cells seems to be different from that of many other yeasts or fungi. Electron microscopy has shown that the cell wall of Malassezia species is relatively thick and has a multilaminar ultrastructure along with characteristic invaginations of the innermost layer (Mittag, 1995).

In this study, we isolated the cell wall polysaccharides from M. furfur and M. pachydermatis, and determined their chemical structures. Unexpectedly, the polysaccharide was galactomannan, which was mostly composed of galactofuranosyl residues with a small amount of mannosyl residues. The galactomannan was found to have linear $\beta$ 1,6-linked galactofuranosyl polymer chains attached to the small core mannan. This structure is different from the galactomannan of Aspergillus fumigatus, which contains linear $\beta$-1,5-linked galactofuranosyl oligosaccharide sidechains (Latgé et al., 1994), and that of Trichophyton rubrum, which has single terminal $\beta$-galactofuranosyl sidechains (Ikuta et al., 1997). The galactomannan from $M$. furfur did not cross-react with anti-A. fumigatus and antiC. albicans antibodies. Therefore, we postulate that the galactomannan acts as a Malassezia-specific antigen.

\section{METHODS}

Strains and culture conditions. Malassezia furfur NBRC 0656 (=CBS 1878), Malassezia pachydermatis NBRC 10064 (=CBS 1879), Fonsecaea pedrosoi NBRC 6733 and Exophiala jeanselmei NBRC 6857 were obtained from the NITE Biological Resource Center (NBRC) of the National Institute of Technology and Evaluation (NITE), Tokyo, Japan. Yeast cells were grown at $30{ }^{\circ} \mathrm{C}$ with shaking in YPD liquid medium supplemented with olive oil ( $1 \%$ yeast extract, $2 \%$ peptone, $2 \%$ glucose, $1 \%$ olive oil) for $48 \mathrm{~h}$.
Materials. The $p$-aminobenzoic acid ethyl ester (ABEE) labelling kit was from Seikagaku. The factor 1 serum of Candida Check, which contains an anti- $\alpha-1,2$-mannoside antibody, was from Iatron. The Platelia Aspergillus ELISA kit for detection of the Aspergillus galactomannan antigen was from Bio-Rad. The anti- $\beta$-1,3-glucan antibody, a mouse monoclonal IgG, was from Biosupplies (Australia). The cell wall polysaccharides of C. albicans J-1012 (serotype A) and T. rubrum NBRC 5467 were the same specimens as used in previous studies (Ikuta et al., 1997; Shibata et al., 2007).

Animals and immunization schedule. The anti-M. furfur antibody was prepared by immunizing two New Zealand White rabbits (weighing approximately $2.5 \mathrm{~kg}$ ) with whole heat-killed $M$. furfur yeast cells. A pre-immune serum sample was collected as the negative control before the primary immunization. Each rabbit was subcutaneously immunized with a $4 \mathrm{ml}$ portion of $10^{8} \mathrm{M}$. furfur cells emulsified in Freund's complete adjuvant $(1: 1, \mathrm{v} / \mathrm{v})$ at eight sites along the back. Two and four weeks later, the rabbits were subcutaneously boosted with a $4 \mathrm{ml}$ portion of $10^{8} \mathrm{M}$. furfur cells emulsified in Freund's incomplete adjuvant $(1: 1, \mathrm{v} / \mathrm{v})$. The rabbits were bled 10 days after the last injection, and the sera were collected and stored at $-20{ }^{\circ} \mathrm{C}$. The ELISA titre of the anti- $M$. furfur antibody was $1 / 20000$.

Carbohydrate composition analysis. For analysis of the carbohydrate composition, the polysaccharides and dried cells were hydrolysed with $4 \mathrm{M}$ trifluoroacetic acid (TFA) at $100{ }^{\circ} \mathrm{C}$ for $3 \mathrm{~h}$. The resulting monosaccharide mixtures were converted into ABEE derivatives according to the manufacturer's instructions, and analysed by HPLC using a TSK-GEL ODS-120T column $(4.6 \times 150 \mathrm{~mm})$ (Tosoh). Elution was done with a $93: 7(\mathrm{v} / \mathrm{v})$ mixture of $0.2 \mathrm{M}$ potassium borate buffer ( $\mathrm{pH} \mathrm{8.9)}$ and acetonitrile, and the eluates were monitored at $305 \mathrm{~nm}$. Specific optical rotation of the monosaccharide was measured using a P-2300 polarimeter (JASCO) for determination of the absolute configuration.

Preparation of fluorescein-conjugated stearoyl dextran (FITCstearoyl dextran). The dextran was first stearoylated. A $200 \mathrm{mg}$ sample of the dextran $(70 \mathrm{kDa})$ was dissolved in $5 \mathrm{ml}$ DMSO. Stearoyl chloride, $0.6 \mathrm{ml}$, was added dropwise to the solution and allowed to react overnight at $25{ }^{\circ} \mathrm{C}$ with stirring. Stearoyl chloride was decomposed by the addition of $1 \mathrm{ml}$ water followed by evaporation to dryness. The reaction product was washed three times with 2-propanol, then dialysed and lyophilized. For the fluorescein labelling, the stearoyl dextran was dissolved in $5 \mathrm{ml}$ DMSO. To this solution, two drops of pyridine, $20 \mathrm{mg}$ FITC and $4 \mathrm{mg}$ dibutyltin dilaurate were added and allowed to react at $95{ }^{\circ} \mathrm{C}$ for $2 \mathrm{~h}$. The reaction product, FITC-stearoyl dextran, was recovered by ethanol precipitation (de Belder \& Wik, 1975).

Flow cytometry. For preparation of the heat-killed yeasts, live Malassezia cells were suspended in PBS, and incubated at $90{ }^{\circ} \mathrm{C}$ for $20 \mathrm{~min}$ and washed with PBS. To analyse the cell surface polysaccharides, $10^{6}$ cells were incubated for $30 \mathrm{~min}$ with $2 \%$ BSAPBS. After washing, the cells were incubated for $30 \mathrm{~min}$ with factor 1 serum ( $1: 300$ dilution in $1 \%$ BSA-PBS), antibody to $M$. furfur cells ( $1: 400$ dilution in $1 \%$ BSA-PBS), or antibody to $\beta$-1,3-glucans $(1: 50$ dilution in $1 \%$ BSA-PBS). After washing, the cells were incubated for 30 min with specific FITC-labelled secondary antibodies (1:100 dilution in $1 \%$ BSA-PBS). The negative control was performed by adding a labelled second antibody at the same concentration. All processes were conducted at $4{ }^{\circ} \mathrm{C}$. After washing, the cells were fixed in $0.4 \%$ paraformaldehyde. Flow cytometry was performed using a FACSCalibur system (Becton Dickinson).

Cell surface hydrophobicity. Cell surface hydrophobicity was determined by staining the cells with FITC-stearoyl dextran. Cells 
grown at 25 and $37{ }^{\circ} \mathrm{C}$ were washed with PBS, suspended in PBS to a concentration of $2 \times 10^{6}$ cells ml $^{-1}$ and stained with FITC-stearoyl dextran $\left(100 \mu \mathrm{g} \mathrm{ml}^{-1}\right)$ for $1 \mathrm{~h}$. As the control, FITC-dextran was used at the same concentration. All processes were conducted at $4{ }^{\circ} \mathrm{C}$. After washing with PBS, the cells were fixed in $0.4 \%$ paraformaldehyde and examined by flow cytometry. A hydrophobic microsphere assay developed by Hazen \& Hazen (1987) was also conducted for comparison. From a stock $10 \%$ solids suspension of polystyrene microspheres $(0.8 \mu \mathrm{m}$ diameter; Bangs Laboratories), $6 \mu \mathrm{l}$ was taken and added to $2 \mathrm{ml}$ buffer. Equal volumes $(100 \mu \mathrm{l})$ of the cell and microsphere suspensions were combined in glass tubes and mixed in a vortex mixer for $30 \mathrm{~s}$. Microsphere attachment was assessed by microscopy at $400 \times$ magnification. The percentage of cells with three or more attached spheres was recorded as the percentage hydrophobicity.

Preparation of cell wall polysaccharide. The cells were washed and dehydrated with acetone, and the crude cell wall polysaccharide was extracted with water at $120{ }^{\circ} \mathrm{C}$ for $2 \mathrm{~h}$. The extract was dialysed against running tap water and then lyophilized. The dialysate was dissolved in water and centrifuged at $13000 \mathrm{~g}$ for $20 \mathrm{~min}$ to eliminate any insoluble material. The supernatant was applied onto a column $(70 \times 4 \mathrm{~cm})$ of Sephacryl S-100 and eluted with water. Aliquots of the eluates were assayed for their carbohydrate and protein contents by the phenol/sulfuric acid method (Dubois et al., 1956) and BCA protein assay kit (Pierce), respectively. Eluates corresponding to the top peak containing the polysaccharide were combined and lyophilized. The cell wall polysaccharide was fractionated using DEAE-Sepharose chromatography by stepwise elution with water, and $0.1 \mathrm{M}$ and $0.2 \mathrm{M} \mathrm{NaCl}$. The yields of these fractions were about 60,20 and $20 \%$, respectively. Since the two latter fractions contained a large amount of $\beta$-glucan, judging from the ${ }^{1} \mathrm{H}$-NMR spectra and carbohydrate composition analysis, a structural study of the polysaccharide was performed using the water-eluted fraction.

Hydrolysis of the polysaccharide. For the preparation of the fragment oligosaccharides, the cell wall polysaccharide was partially hydrolysed with $0.15 \mathrm{M}$ TFA at $100{ }^{\circ} \mathrm{C}$ for $10 \mathrm{~min}$. For the preparation of the core mannan, all of the galactofuranosyl residues were removed by treatment with $0.1 \mathrm{M} \mathrm{HCl}$ at $100{ }^{\circ} \mathrm{C}$ for $30 \mathrm{~min}$. After neutralization, the reaction products were separated on a column $(2.5 \times 100 \mathrm{~cm})$ of Bio-Gel P-2. The structure of the fragment oligosaccharides from dimer to pentamer was confirmed by NMR spectroscopy.

NMR spectroscopy. Samples were exchanged twice in ${ }^{2} \mathrm{H}_{2} \mathrm{O}$ with intermediate lyophilization, then dissolved at $1 \%(\mathrm{w} / \mathrm{v})$ in ${ }^{2} \mathrm{H}_{2} \mathrm{O}$ $\left(99.97 \%\right.$ atom $\left.{ }^{2} \mathrm{H}\right)$. The NMR spectra were recorded using JNM-LA600 spectrometers (JEOL) at $45{ }^{\circ} \mathrm{C}$. The total correlation spectroscopy (TOCSY), 2D nuclear Overhauser enhancement spectroscopy (NOESY), distortionless enhancement by polarization transfer 135 (DEPT-135), 2D heteronuclear single quantum coherence spectroscopy (HSQC), and 2D heteronuclear multiple bond coherence spectroscopy (HMBC) were performed using the standard pulse sequence. The proton and carbon chemical shifts were referenced relative to the internal acetone at $\delta 2.225$ and 31.07 , respectively.

ELISA. The polysaccharide $\left(100 \mu \mathrm{g} \mathrm{ml}^{-1}\right.$ in $50 \mathrm{mM}$ carbonate buffer, $\mathrm{pH}$ 9.6) was immobilized overnight onto a microtitre plate at $4{ }^{\circ} \mathrm{C}$. The non-specific binding sites were blocked with $2 \%$ BSA-PBS for $2 \mathrm{~h}$ at room temperature. After incubation with the primary antibodies (diluted from 27- to 500000 -fold in blocking solution) for $2 \mathrm{~h}$ at room temperature, the wells were washed three times with PBS-T (PBS containing $0.05 \%$ Tween 20). After washing with PBS-T, horseradish peroxidase-conjugated antibody $(1: 4000$ dilution in blocking solution) was added and incubated for $2 \mathrm{~h}$ at room temperature. After washing, a substrate solution of $0.01 \%$ o- phenylenediamine and $0.03 \% \mathrm{H}_{2} \mathrm{O}_{2}$ in $150 \mathrm{mM}$ citrate buffer ( $\mathrm{pH}$ 5.0) was added. The reaction was stopped with $2 \mathrm{M} \mathrm{H}_{2} \mathrm{SO}_{4}$ and the $A_{492}$ was measured using an ELISA plate reader (Tosoh).

Platelia Aspergillus ELISA. The reactivity of the galactomannans was determined according to the manufacturer's instructions. Briefly, $50 \mu \mathrm{l}$ of a reaction mixture containing the horseradish peroxidaseconjugated anti-galactomannan monoclonal antibody was added to each well of a microtitre plate coated with the same monoclonal antibody and then $50 \mu \mathrm{l}$ of the sample was added. After $90 \mathrm{~min}$ incubation at $37^{\circ} \mathrm{C}$, the plates were washed five times with washing buffer, then $200 \mu \mathrm{l}$ of the buffer containing tetramethylbenzidine solution was added. The plates were incubated for another $30 \mathrm{~min}$ in the dark at room temperature, after which $100 \mu \mathrm{l}$ of $0.75 \mathrm{M}$ sulfuric acid was added to stop the reaction. The $A_{450}$ was read.

Total carbohydrate content. This was determined by the phenol/ sulfuric acid method (Dubois et al., 1956) with D-mannose as the standard.

\section{RESULTS}

\section{Antigenicity of M. furfur and M. pachydermatis cells}

We first tested the reactivity of these cells with the anti- $\alpha$ 1,2-mannoside and anti- $M$. furfur antibodies. As shown in Fig. 1(a), a flow cytometric analysis revealed that the anti$\alpha$-1,2-mannoside antibody, factor 1 serum of Candida Check, did not cross-react with the M. furfur and $M$. pachydermatis cells, suggesting that the exposed mannan on the cell surface is very small. Similarly, the anti-M. furfur antibody showed weak reactivity to the C. albicans cells. We next examined whether the $\beta$-glucan layer was covered by other cell surface polysaccharides, using the anti- $\beta-1,3-$ glucan antibody. Unlike in $C$. albicans, the $\beta$-1,3-glucan was constitutively expressed on the surface of the Malassezia cells (Fig. 1b). This result suggests that Malassezia cells have fewer polysaccharides on the outside of the $\beta$-glucan layer compared to C. albicans cells.

\section{Comparison of cell surface hydrophobicity}

Variation in growth temperature is one of the factors that is known to affect the hydrophobicity of C. albicans (Hazen et al., 1991). Therefore, cells grown at 25 and $37{ }^{\circ} \mathrm{C}$ were stained with FITC-stearoyl dextran and analysed by flow cytometry. This assay method, which does not use polystyrene microspheres and microscopy, showed that the cell surface of the Malassezia species grown at $37{ }^{\circ} \mathrm{C}$ has a strong hydrophobicity compared to that of C. albicans J1012 (Fig. 1c). In the case of M. furfur, hydrophobicity of the cells grown at $25{ }^{\circ} \mathrm{C}$ was slightly stronger than that of the cells grown at $37{ }^{\circ} \mathrm{C}$. However, for M. pachydermatis the hydrophobicity was almost the same for the cells grown at 25 and at $37^{\circ} \mathrm{C}$. As a control experiment, the hydrophobicity of the same cells was also determined by a hydrophobic microsphere assay. As shown in Table 1, the results corroborated those obtained by the FITC-stearoyl dextran method. 
(a) anti- $\alpha-1,2-$ mannoside
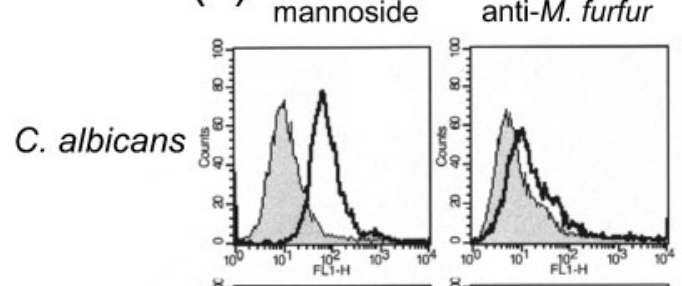

M. furfur
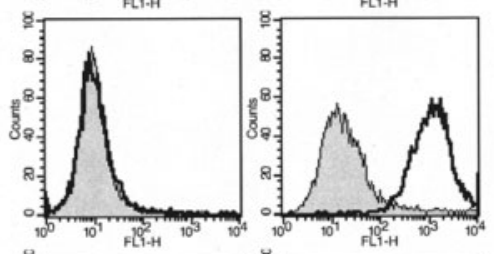

M. pachydermatis
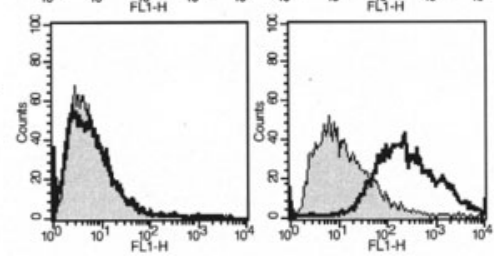

(b)
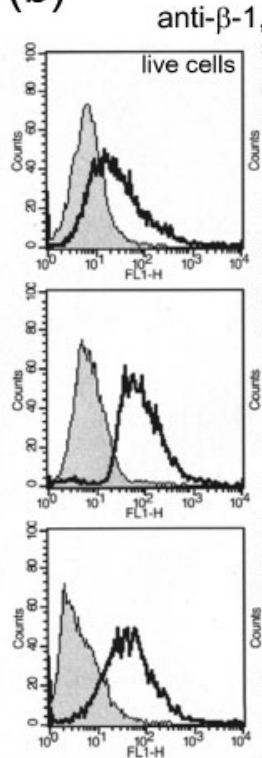

(c)
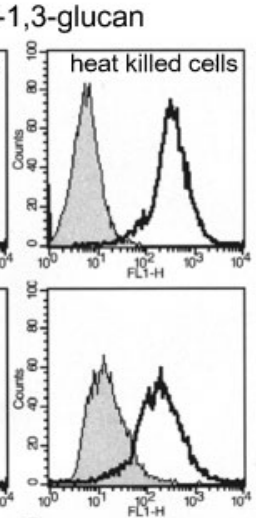

FITC-stearoyl-dextran
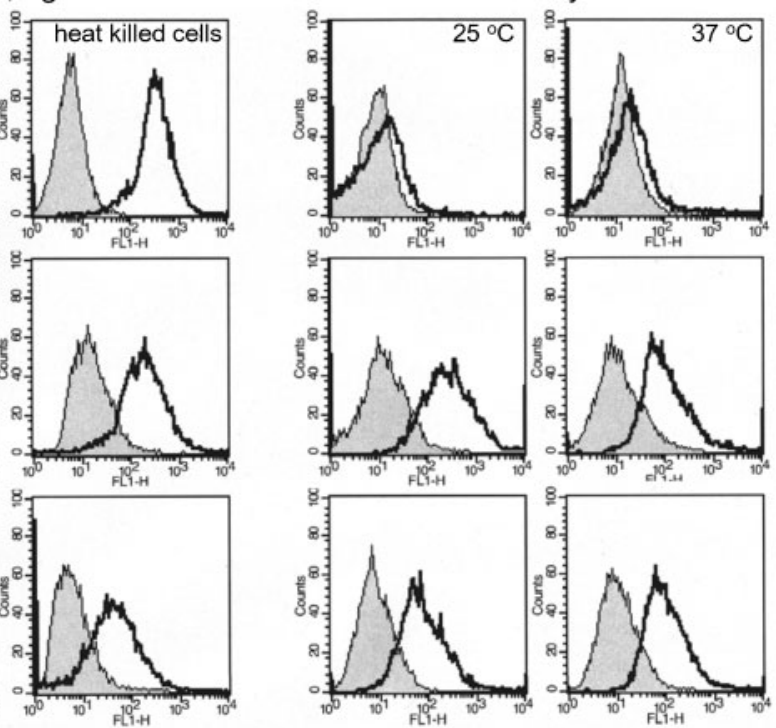

Fig. 1. Flow cytometry of $C$. albicans, $M$. furfur and $M$. pachydermatis. (a) Anti- $\alpha-1,2$-mannoside antibody and anti-M. furfur antibody staining of live cells. (b) Anti- $\beta-1,3$-glucan antibody staining of live or heat-killed cells. (c) FITC-stearoyl dextran staining of live cells grown at 25 and $37^{\circ} \mathrm{C}$.

\section{Structure of cell wall polysaccharide}

The carbohydrate composition of the cells of $M$. furfur, $M$. pachydermatis and C. albicans is shown in Table 2 . Compared with $C$. albicans, the amount of mannose in both Malassezia species was much lower, and, unlike $C$. albicans, the Malassezia species contained galactose. This carbohydrate composition may explain the lack of or reduced reactivity of the Malassezia cells to the anti- $\alpha-1,2-$ mannoside antibody. The cell wall polysaccharide of the Malassezia species was extracted with water at $120{ }^{\circ} \mathrm{C}$ for $2 \mathrm{~h}$, and fractionated using Sephacryl S-100 and DEAESepharose column chromatography. Analysis of the carbohydrate composition of the main polysaccharide fraction, the water-eluted fraction from DEAE-Sepharose, showed that the galactose:mannose ratio was around $15: 1$, indicating that the polysaccharide was galactoman-

Table 1. Cell surface hydrophobicity of cells grown at 25 and $37{ }^{\circ} \mathrm{C}$

Data are presented as the mean (sample standard deviation) $(n=5)$.

\begin{tabular}{|lcc|}
\hline & \multicolumn{2}{c|}{ Hydrophobicity (\%) } \\
\cline { 2 - 3 } & $\mathbf{2 5}{ }^{\circ} \mathbf{C}$ & $\mathbf{3 7}{ }^{\circ} \mathbf{C}$ \\
\hline C. albicans J-1012 & $26.1(2.4)$ & $20.6(5.6)$ \\
M. furfur NBRC 0656 & $83.0(4.2)$ & $85.5(4.8)$ \\
M. pachydermatis NBRC 10064 & $86.8(3.9)$ & $87.3(6.0)$ \\
\hline
\end{tabular}

nan. Since the galactose:mannose ratio of the 0.1 and $0.2 \mathrm{M} \mathrm{NaCl}$ eluted fractions from DEAE-Sepharose was around $5: 2$ and $1: 2$, respectively (data not shown), the galactomannan seemed to have a high heterogeneity regarding the length of the galactosyl moiety. The absolute configuration of galactose was determined by analysis of the specific optical rotation. The result $\left([\alpha]_{\mathrm{D}}+80.2^{\circ}, c 0.2\right.$, water) indicated that the galactose had the $\mathrm{D}$-configuration. The ${ }^{1} \mathrm{H}$-NMR spectra of the galactomannans of $M$. furfur and M. pachydermatis were exactly the same (Fig. 2a, b). The extracellular polysaccharides isolated from the culture filtrate of these two species also exhibited the same ${ }^{1} \mathrm{H}$ NMR spectra (data not shown). Fig. 2(c) and Fig. 2(d)

Table 2. Carbohydrate composition of whole cells and cell surface polysaccharides

\begin{tabular}{|lccc|}
\hline & \multicolumn{3}{c|}{ Carbohydrate residue (\%) } \\
\cline { 2 - 4 } & Galactose & Mannose & Glucose \\
\hline Whole cells & & & \\
C. albicans & 0 & 10 & 90 \\
M. furfur & 2 & 1 & 97 \\
M. pachydermatis & 2 & 1 & 97 \\
Cell surface polysac- & & & \\
$\quad$ charide & & & \\
C. albicans & 0 & 100 & 0 \\
M. furfur & 85 & 6 & 9 \\
M. pachydermatis & 84 & 11 & 5 \\
\hline
\end{tabular}



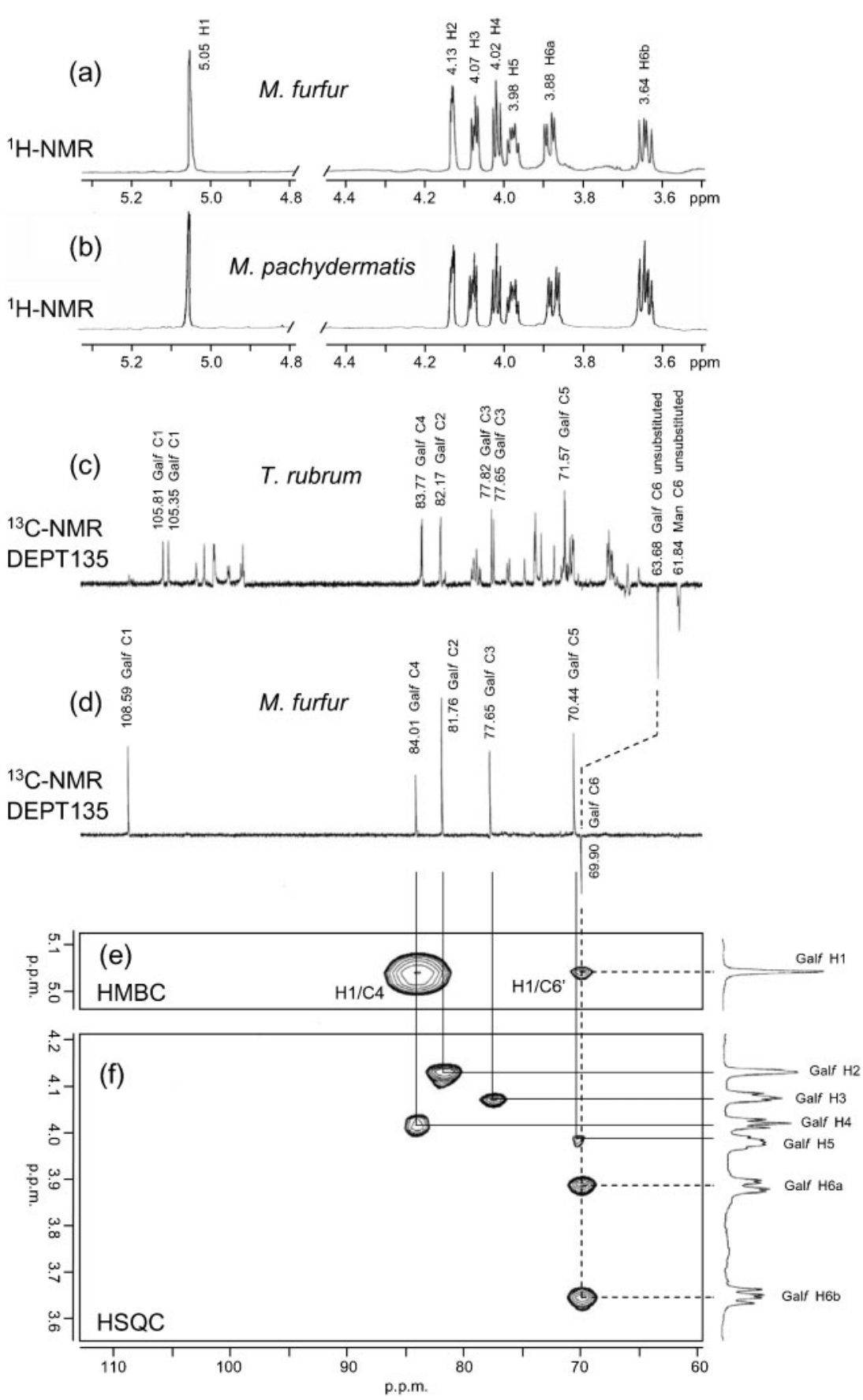

Fig. 2. NMR spectra of galactomannans: ${ }^{1} \mathrm{H}-$ NMR spectra of $M$. furfur (a) and $M$. pachydermatis (b); ${ }^{13} \mathrm{C}-N M R$ DEPT-135 spectra of T. rubrum (c) and M. furfur (d); HMBC (e) and HSQC ( $f$ ) spectra of $M$. furfur. Dashed lines between the two ${ }^{13} \mathrm{C}-\mathrm{NMR}$ DEPT-135 spectra indicate the downfield shift of the C- 6 carbon of the galactofuranosyl residue caused by glycosylation with other galactofuranosyl residues. Galf, D-galactofuranosyl residue. show the ${ }^{13} \mathrm{C}$-NMR DEPT-135 spectra of the T. rubrum and $M$. furfur galactomannans, respectively. The negative signals in these spectra correspond to C-6 of the carbohydrates. As shown in Fig. 2(d), the M. furfur galactomannan had characteristic signals for galactofuranosyl residues $(\mathrm{C}-1, \delta 108.59$; C-2 $\delta$ 81.76; C-3, $\delta$ 77.65) (Table 3). However, the C-6 signal of the M. furfur galactomannan appeared at $\delta 69.90$ instead of around $\delta$ 63.7, which corresponds to the C-6 of the terminal galactofuranosyl residues found in the galactomannan of T. rubrum. The downfield shift of the C-6 signal on $M$. furfur galactomannan indicates that the polysaccharide consisted of linear 1,6-linked galactofuranosyl residues. The coupling constant of the anomeric proton of the galactofuranosyl residues was around $1.8 \mathrm{~Hz}$, which corresponds to the $\beta$ anomeric configuration (Cyr \& Perlin, 1979). This is also supported by the chemical shifts of their anomeric carbons $(\delta>106$ p.p.m.). To confirm this structure, an HMBC experiment was carried out. The presence of the intraresidue cross-peak H-1/C-4 shows the furanosidic character of the galactose, and the interresidue cross-peak H-1/C-6' demonstrates the $\beta$-1,6-linkage indi- 
Table 3. ${ }^{1} \mathrm{H}$ and ${ }^{13} \mathrm{C}$ NMR chemical shifts of the galactomannan isolated from $M$. furfur $(\delta$, p.p.m.) $(J=\mathrm{Hz})$

\begin{tabular}{|lcc|}
\hline & \multicolumn{2}{c|}{ Galf } \\
\cline { 2 - 3 } & ${ }^{1} \mathbf{H}$ & ${ }^{13} \mathbf{C}$ \\
\hline H1 $\left({ }^{3} J_{1,2}\right)$ & $5.05(1.8)$ & 108.59 \\
H2 $\left({ }^{3} J_{2,3}\right)$ & $4.13(3.6)$ & 81.76 \\
H3 $\left({ }^{3} J_{3,4}\right)$ & $4.07(6.0)$ & 77.65 \\
H4 $\left({ }^{3} J_{4,5}\right)$ & $4.02(4.8)$ & 84.01 \\
H5 $\left({ }^{3} J_{5,6}\right)$ & $3.98(3.6)$ & 70.44 \\
H6a $\left({ }^{3} J_{5,66}\right)$ & $3.88(7.2)$ & 69.90 \\
H6b $\left({ }^{3} J_{6,6 a}\right)$ & $3.64(10.8)$ & - \\
\hline
\end{tabular}

cated above (Fig. 2e). The NOESY spectrum also contained the interresidue cross-peak $\mathrm{H}-1 / \mathrm{H}-6^{\prime}$ (data not shown). The proton and carbon signals of the galactomannan were assigned by the HSQC (Fig. 2f) and COSY experiments.

In order to obtain information about the core mannan structure of the galactomannan, the polysaccharide was subjected to partial hydrolysis with dilute acid, which selectively removed the galactofuranosyl residues. Around $5 \%$ of a residual polysaccharide, composed only of mannose, was obtained. The ${ }^{1} \mathrm{H}-\mathrm{NMR}$ spectrum of the

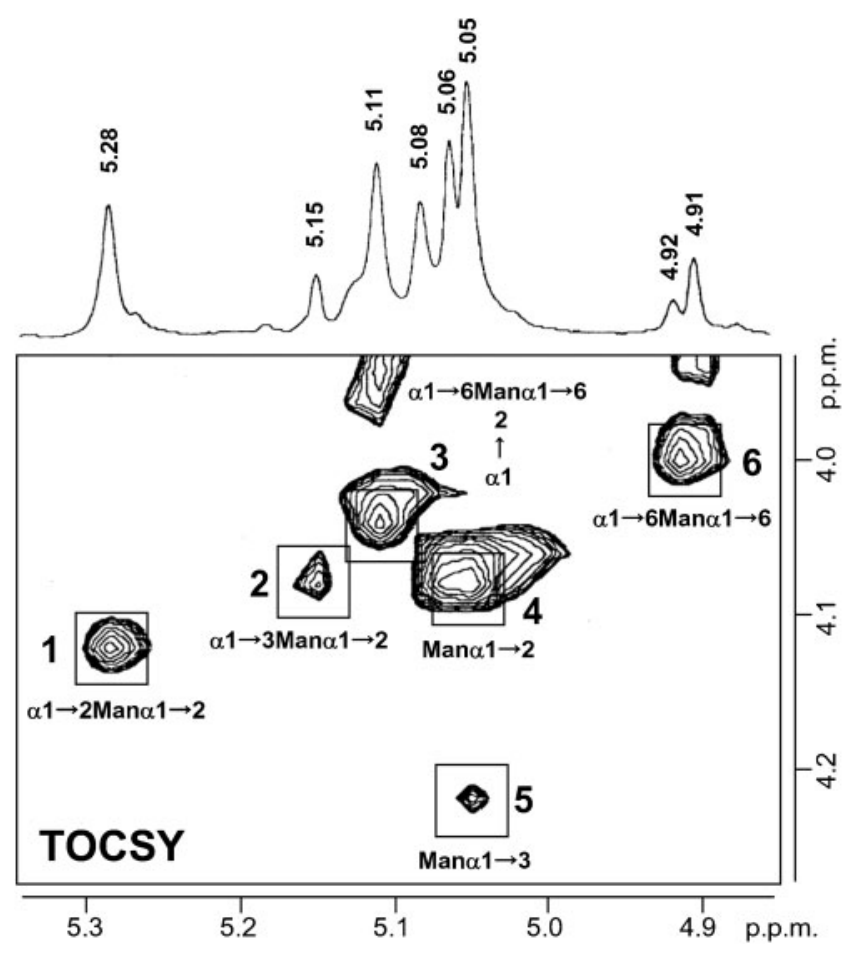

Fig. 3. NMR spectrum of the mannan core of the galactomannan obtained from $M$. furfur. The boxed regions in the TOCSY spectrum indicate the $\mathrm{H}-1-\mathrm{H}-2$-correlated cross-peaks of the $\alpha$ mannosyl residues. These cross-peaks were common to those of the mannans from C. albicans and S. cerevisiae.

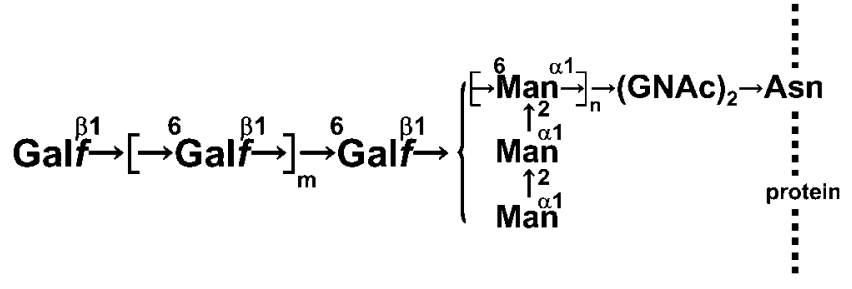

Fig. 4. One of the possible structures of $M$. furfur and $M$. pachydermatis. Galf and Man denote the D-galactofuranosyl and $D$-mannopyranosyl residues, respectively. The $m$ in the structure was estimated to be around 30 from the ratio of the signal dimensions of galactofuranosyl residues. The $\mathrm{n}$ indicates that the core mannan has a comb-like structure but we could not determine the number in this study. The long linear $\beta-1,6$-linked galactofuranosyl polymer chain is linked to a core mannan which has a comblike structure.

mannan is shown in Fig. 3. The presence of the signal at $\delta$ 4.91-4.92, cross-peak 6, indicates that this mannan contains the linear $\alpha$-1,6-linked backbone mannosyl residues. Furthermore, the signals at $\delta$ 5.05-5.06, crosspeak 4 , and the signal at $\delta 5.28$, cross-peak 1 , correspond to the nonreducing terminal and intermediate $\alpha$-1,2-linked mannosyl residues, respectively. The core mannan also contains a small amount of the nonreducing terminal $\alpha$ 1,3-linked mannosyl residues connected to the $\alpha$-1,2-linked ones, judging from the presence of cross-peaks $2(\mathrm{H} 1 / \mathrm{H} 2, \delta$ $5.15 / 4.08)$ and $5(\mathrm{H} 1 / \mathrm{H} 2, \delta 5.05 / 4.23)$ (Shibata et al., 2007). These results suggest that the core mannan has a comb-like structure similar to the mannans of $S$. cerevisiae and C. albicans.

On the basis of these results, in Fig. 4 we depict one possible chemical structure for the cell wall galactomannan of $M$. furfur and M. pachydermatis. The average degree of polymerization of the galactofuranose was estimated to be around 30 from the ratio of the total $\mathrm{H}-1$ and nonreducing terminal H-6 signal dimensions of the galactofuranosyl residues (Wieneke et al., 2007).

\section{Antigenic cross-reactivity between galactomannans}

Many fungi have galactofuranose-containing polysaccharides in their cell wall. Therefore, we tested the antigenic similarity of the galactomannan of $M$. furfur to other galactomannans using the anti- $\beta$-1,5-linked galactofuranosyl monoclonal antibody of the Platellia Aspergillus ELISA kit. At $10 \mathrm{ng} \mathrm{ml}^{-1}$, the galactomannans from M. furfur, $M$. pachydermatis and T. rubrum, and from the dematiaceous fungi $F$. pedrosoi and E. jeanselmei, showed no reactivity, suggesting that the galactomannans from the Malassezia species do not contain $\beta$-1,5-linked galactofuranosyl residues and have a completely different antigenicity from that of A. fumigatus (Fig. 5). 


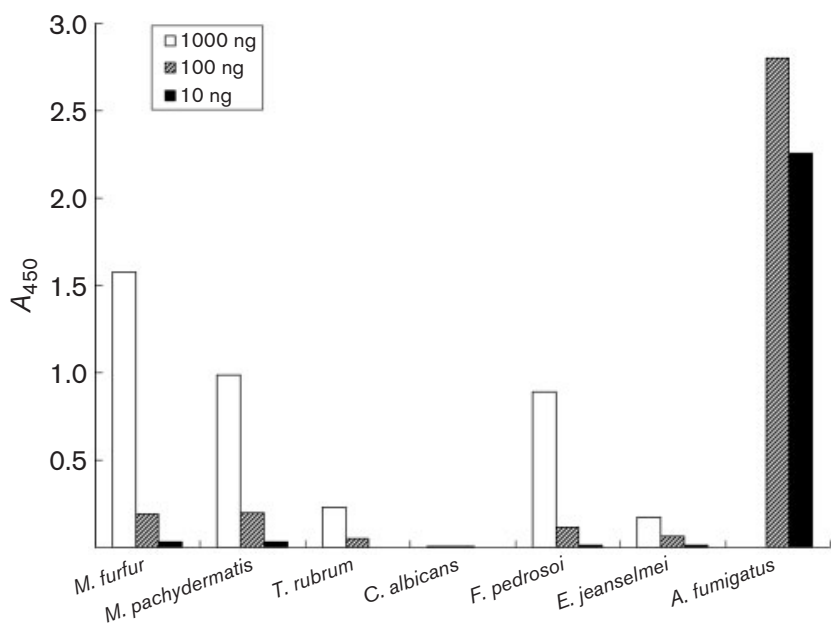

Fig. 5. Platelia Aspergillus ELISA of galactomannans and mannan obtained from various pathogenic fungi.

Next, we tested the reactivity of several fungal polysaccharides with the anti- $M$. furfur and anti- $\alpha-1,2$-mannoside antibodies by ELISA (Fig. 6). The galactomannans of $M$. furfur and $M$. pachydermatis showed strong reactivity with the anti-M. furfur antibody. In contrast, the mannan of $C$. albicans and the galactomannans of T. rubrum, F. pedrosoi and E. jeanselmei showed no or less reactivity. Taken together, these results indicate that the cell surface of $M$. furfur and $M$. pachydermatis possesses galactomannan which has no cross-reactivity with other galactomannans from pathogenic fungi and behaves as a Malassezia-specific antigen.

\section{Identification of epitopes}

In order to identify the Malassezia-specific antigen, the effect of $\beta$-1,6-linked galactofuranosyl oligomers of increasing length, obtained by partial acid hydrolysis of the galactomannan, was studied in ELISA inhibition experiments using the anti-M. furfur antibody. As shown in Fig. 7, the tetramer and pentamer showed almost the same strong inhibitory effect. This result indicates that the anti-M. furfur antiserum contains a specific antibody which recognizes the $\beta$-1,6-linked galactofuranosyl tetramer moieties of the M. furfur galactomannan.

\section{DISCUSSION}

We could not obtain a mannan from crude hot-water extracts of $M$. furfur and M. pachydermatis by the Fehling's solution precipitation method. Furthermore, these cells did not react with the anti- $\alpha-1,2$-mannoside antibody. A carbohydrate composition analysis of the whole cells indicated that there is a small amount of mannose in addition to galactose, suggesting that the Malassezia cells

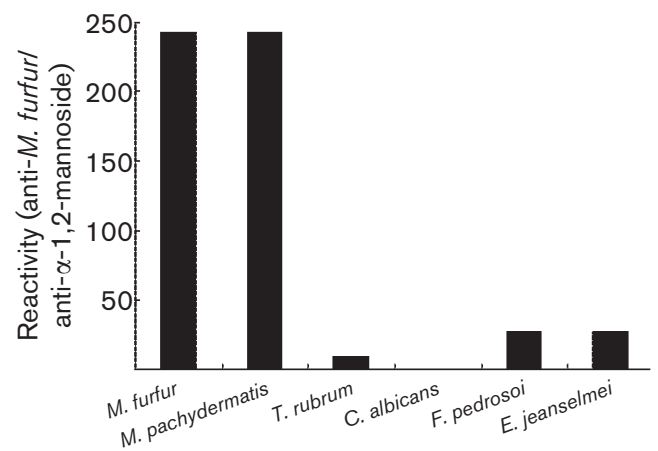

Fig. 6. Reactivity of the anti-M. furfur antibody with galactomannans and mannan obtained from various pathogenic fungi. One unit of reactivity was defined as an $A_{492}$ of 0.25 in the ELISA. Reactivity is expressed as the ratio (reactivity units with anti- $M$. furfur antibody)/(reactivity units with anti- $\alpha-1,2$-mannoside antibody). These results are representative of three independent experiments.

have fewer polysaccharides on the outside of the $\beta$-glucan and chitin layer compared to C. albicans cells. Mathov et al. (1996) reported that a psoriasis patient's serum reacted with 100 and $120 \mathrm{kDa}$ bands of a French press extract of $M$. furfur cells. They showed that the reaction pattern was the same as that of a lectin which recognizes $\mathrm{N}$-acetylglucosamine (GlcNAc), and that the reaction with the serum was inhibited by GlcNAc. Furthermore, one of the bands was digested by lyticase ( $\beta$-1,3-glucanase), suggesting that these bands were glycoproteins containing cell wall $\beta$-glucan and chitin. Taken together, these results suggest that the cell wall chitin, a polymer of GlcNAc, in addition to $\beta$-glucan, is exposed at the cell surface and acts as an antigen. This would be consistent with our findings of the low mannose content of the cell wall polysaccharide and the reactivity of Malassezia cells with the anti- $\beta$-1,3-glucan antibody.

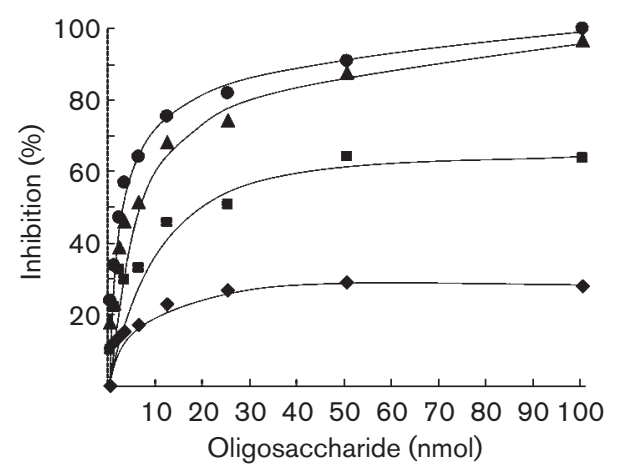

Fig. 7. Inhibition of ELISA by galactofuranooligosaccharides. To the $M$. furfur galactomannan-coated plate, anti- $M$. furfur antibody pretreated or not with haptenic galactofuranooligosaccharides $(\boldsymbol{\nabla}$, dimer; $\mathbf{\square}$, trimer; $\boldsymbol{\Lambda}$, tetramer; $\boldsymbol{\bullet}$, pentamer) was added, followed by incubation for $2 \mathrm{~h}$ at room temperature; the bound antibody was detected as described in Methods. 
Cell surface hydrophobicity plays an important role in the pathogenicity of micro-organisms. Hydrophobic C. albicans cells are more adherent than hydrophilic cells to a variety of host tissues (Hazen et al., 1991). For the detection of the hydrophobicity of a yeast cell surface, Hazen \& Hazen (1987) developed an assay method involving two processes, adhesion of polystyrene beads to the yeast cells and counting of the bead-adhered cells by microscopy. Colling et al. (2005) introduced flow cytometry for the hydrophobicity assay. In this method, the fluorescence of blue-dyed polystyrene beads is utilized for counting the bead-adhered cells during flow cytometry, and a gate is applied to distinguish the bead-adhered cells from the nonbead-adhered cells. The FITC-stearoyl dextran method for determining hydrophobicity is simpler than these assay systems, and the hydrophobicity levels obtained by this method are similar to those obtained with the polystyrene microsphere method. C. albicans cells are hydrophobic when grown at $25{ }^{\circ} \mathrm{C}$ and hydrophilic at $37{ }^{\circ} \mathrm{C}$ (Hazen et al., 1991). However, Malassezia cells did not show hydrophilicity when grown at $37^{\circ} \mathrm{C}$. It has been reported that the Malassezia cell wall has a multilaminar structure (Mittag, 1995). Since the lamellar structure varies with the different lipid sources in the medium and stains with Nile blue sulfate, it is suggested that the cell wall contains lipid. The cell wall lipid seems likely to be responsible for the hydrophobicity interaction of the FITCstearoyl dextran in Malassezia species.

Galactofuranose-containing glycoproteins or polysaccharides are known to be present in fungi, bacteria, protozoa, green algae and cyanobacteria. The galactofuranosyl residue makes a variety of linkages, such as $\beta-1,2-, \beta-1,3-$, $\beta-1,5-, \quad \beta-1,6-, \quad$ and some $\alpha$-linkages, and is highly immunogenic (Notermans et al., 1988). The galactofuranosyl residue is essential for the survival or virulence of some pathogenic micro-organisms (Pan et al., 2001). In fungi, galactofuranosyl residues have been found in Aspergillus, Penicillium, Histoplasma, Paracoccidioides, Trichophyton and Fonsecaea species (Barr et al., 1984; Gander et al., 1974; Ikuta et al., 1997; Latgé et al., 1994; Levery et al., 1996; Suzuki \& Takeda, 1977). The galactofuranosyl residues of Aspergillus and Penicillium are composed of $\beta$-1,5-linked oligosaccharide side chains. On the other hand, $\beta$-1,6-linked galactofuranosyl residues are present in the cell wall polysaccharide or glycolipid of Mycobacterium tuberculosis (Daffé et al., 1990), Paracoccidioides brasiliensis (Levery et al., 1996) and Streptococcus oralis (Abeygunawardana et al., 1991). However, these carbohydrate moieties have a single terminal or single internal $\beta$-1,6-linked galactofuranosyl residue or alternating $\beta$-1,6-linked galactofuranosyl and $\beta$ 1,5-linked galactofuranosyl residues. Although some galactomannans have consecutive $\beta$-1,6-linked galactofuranosyl residues on the main chain, these are almost fully substituted by side chains and have a comb-like structure (Ahrazem et al., 2001). Recently, Wieneke et al. (2007) isolated intracellular $\beta$-1,6-linked galactofuranooligosacchar- ides, up to the decamer, from the terrestrial cyanobactrium Nostoc commune. However, there appear to have been no reports of an antigenic cell wall polysaccharide consisting of consecutive $\beta$-1,6-linked galactofuranosyl residues without side chains. The mannan moiety of the Malassezia galactomannan has a comb-like structure. The side chain of the mannan mainly consists of $\alpha$-1,2-linked mannosyl residues, with a small amount of terminal $\alpha$-1,3-linked mannosyl residues, similar to the mannan of $S$. cerevisiae. Since the proportion of the mannan moiety on the galactomannan is small, it has not yet been determined to which mannosyl residues the galactofuranosyl polymer chains are attached. The anti-M. furfur antibody cross-reacted with C. albicans mannan at a high concentration in ELISA. This result suggests that the anti- $M$. furfur antibody contains an antibody against the $\alpha-1,2$-mannosyl residues, which is consistent with the observation of Lintu et al. (1999).

In this report, we show the results for only two of eleven Malassezia species. However, the reactivity of Malassezia sympodialis cells with the anti-M. furfur antibody was comparable to that of M. furfur and M. pachydermatis cells by FACS analysis (data not shown). Therefore, we postulate that the $\beta$-1,6-linked linear galactofuranosyl polymer structure of the galactomannan is a common antigen in the genus Malassezia.

During the innate immune response, microbial carbohydrate chains are recognized by animal lectins. The mannose receptor and the mannan-binding protein, both of which have an affinity to mannose, are present on cells as phagocytosis receptors or in plasma as opsonins to activate the complement system. Although mannosyl residues are present in mammalian tissues as well as in microorganisms, galactofuranosyl residues are not. Therefore, the recognition of galactofuranosyl residues can effectively induce pathogen-specific cellular responses and fluid-phase immune reactions for elimination. Recently, Tsuji et al. (2001) identified a human intelectin, which is a $\mathrm{Ca}^{2+}$ dependent galactofuranose-binding lectin. Thus, the human intelectin would bind to various pathogens containing galactofuranosyl residues - Malassezia, Aspergillus, Penicillium, Trichophyton, etc. - and may play an immunological role. Most recently, Yamasaki et al. (2009) reported that a C-type lectin, Mincle, on activated macrophages specifically reacts with cells of the genus Malassezia, but does not react with cells of the genera Aspergillus, Candida, Cryptococcus, Trichosporon or Saccharomyces. They reported that the lectin binds to $\alpha$ mannose, but not mannan, and speculated that it recognizes the specific geometry of $\alpha$-mannosyl residues in the genus Malassezia. Although the carbohydrate recognition domain of Mincle contains an EPN (GluPro-Asn) motif (Matsumoto et al., 1999), which is a putative mannose-binding motif, it is possible that Mincle recognizes a Malassezia-specific cell surface component, such as the $\beta$-1,6-galactofuranosyl residue, some kind of hydrophobic molecule or a complex molecule of the $\alpha$ mannosyl residue with these components. 
There appears to be no report describing an identical or similar antigenic structure to the Malassezia galactomannan on the cell wall of pathogenic micro-organisms. Therefore, we can say that the antibody against the $\beta-1,6$ linked galactofuranosyl oligomer has potential as a diagnostic indicator for Malassezia infections of humans and animals by detection of the antigen or the fungal cells themselves. For the routine clinical diagnosis of Malassezia infection, skin scrapings are microscopically examined by $\mathrm{KOH}$ or $\mathrm{KOH}-\mathrm{Calcofluor}$ white preparations, or by staining with periodic acid/Schiff or methylene blue. Since these stainings of the preparations are non-specific for the genus Malassezia, infection by Malassezia has to be diagnosed by its characteristic morphology. In veterinary medicine, M. pachydermatis is the most important species in the genus. M. pachydermatis is most frequently isolated from the skin, mucosa or ear canal of healthy dogs and cats; it acts as an opportunistic secondary pathogen within the ear canal and can cause otitis externa. We can stain Malassezia cells using the enzyme-conjugated antibody which is specific for the galactomannan of the Malassezia cell wall. Therefore, there is the possibility that we can semiquantitatively estimate the amount of Malassezia cells in specimens from the ear canal of a dog or cat by the colour reaction of the enzyme immunoassay, which would be clinically easier and more reliable for the diagnosis of Malassezia infection.

\section{REFERENCES}

Abeygunawardana, C., Bush, C. A. \& Cisar, J. O. (1991). Complete structure of the cell surface polysaccharide of Streptococcus oralis C104: a 600-MHz NMR study. Biochemistry 30, 8568-8577.

Ahrazem, O., Prieto, A., Gómez-Miranda, B., Bernabé, M. \& Leal, J. A. (2001). Comparison of cell-wall polysaccharides from Nectria cinnabarina with those from the group of Nectria with Sesquicillium anamorphs. Microbiology 147, 1839-1849.

Ashbee, H. R. \& Evans, E. G. (2002). Immunology of diseases associated with Malassezia species. Clin Microbiol Rev 15, 21-75.

Bai, C., Xu, X. L., Chan, F. Y., Lee, R. T. \& Wang, Y. (2006). MNN5 encodes an iron-regulated alpha-1,2-mannosyltransferase important for protein glycosylation, cell wall integrity, morphogenesis, and virulence in Candida albicans. Eukaryot Cell 5, 238-247.

Barr, K., Laine, R. A. \& Lester, R. L. (1984). Carbohydrate structures of three novel phosphoinositol-containing sphingolipids from the yeast Histoplasma capsulatum. Biochemistry 23, 5589-5596.

Bates, S., Hughes, H. B., Munro, C. A., Thomas, W. P., MacCallum, D. M., Bertram, G., Atrih, A., Ferguson, M. A., Brown, A. J. \& other authors (2006). Outer chain N-glycans are required for cell wall integrity and virulence of Candida albicans. J Biol Chem 281, 90-98.

Colling, L., Carter, R. N., Essmann, M. \& Larsen, B. (2005). Evaluation of relative yeast cell surface hydrophobicity measured by flow cytometry. Infect Dis Obstet Gynecol 13, 43-48.

Cyr, N. \& Perlin, A. S. (1979). The conformations of furanosides. A ${ }^{13} \mathrm{C}$ nuclear magnetic resonance study. Can J Chem 57, 2504-2511.

Daffé, M., Brennan, P. J. \& McNeil, M. (1990). Predominant structural features of the cell wall arabinogalactan of Mycobacterium tuberculosis as revealed through characterization of oligoglycosyl alditol fragments by gas chromatography/mass spectrometry and by ${ }^{1} \mathrm{H}$ and ${ }^{13} \mathrm{C}$ NMR analyses. J Biol Chem 265, 6734-6743.

Dankner, W. M., Spector, S. A., Fierer, J. \& Davis, C. E. (1987). Malassezia fungaemia in neonates and adults: complication of hyperalimentation. Rev Infect Dis 9, 743-753.

de Belder, A. N. \& Wik, K. O. (1975). Preparation and properties of fluorescein-labelled hyaluronate. Carbohydr Res 44, 251-257.

Devlin, R. K. (2006). Invasive fungal infections caused by Candida and Malassezia species in the neonatal intensive care unit. Adv Neonatal Care 6, 68-77.

Doekes, G. \& van leperen-van Dijk, A. G. (1993). Allergens of Pityrosporum ovale and Candida albicans. I. Cross-reactivity of IgEbinding components. Allergy 48, 394-400.

Dubois, M., Gilles, K. A., Hamilton, J. K., Rebers, P. A. \& Smith, F. (1956). Colorimetric method for determination of sugars and related substances. Anal Chem 28, 350-356.

Faergemann, J. (2002). Atopic dermatitis and fungi. Clin Microbiol Rev 15, 545-563.

Gander, J. E., Jentoft, N. H., Drewes, L. R. \& Rick, P. D. (1974). The 5O- $\beta$-D-galactofuranosyl-containing exocellular glycopeptide of Penicillium charlesii. Characterization of the phosphogalactomannan. J Biol Chem 249, 2063-2072.

Guillot, J. \& Bond, R. (1999). Malassezia pachydermatis: a review. Med Mycol 37, 295-306.

Hazen, K. C. \& Hazen, B. W. (1987). A polystyrene microsphere assay for detecting surface hydrophobicity variations within Candida albicans populations. J Microbiol Methods 6, 289-299.

Hazen, K. C., Brawner, D. L., Riesselman, M. H., Jutila, M. A. \& Cutler, J. E. (1991). Differential adherence of hydrophobic and hydrophilic Candida albicans yeast cells to mouse tissues. Infect Immun 59, 907-912.

Hirai, A., Kano, R., Makimura, K., Duarte, E. R., Hamdan, J. S., Lachance, M. A., Yamaguchi, H. \& Hasegawa, A. (2004). Malassezia nana sp. nov., a novel lipid-dependent yeast species isolated from animals. Int J Syst Evol Microbiol 54, 623-627.

Ikuta, K., Shibata, N., Blake, J. S., Dahl, M. V., Nelson, R. D., Hisamichi, K., Kobayashi, H., Suzuki, S. \& Okawa, Y. (1997). NMR study of the galactomannans of Trichophyton mentagrophytes and Trichophyton rubrum. Biochem J 323, 297-305.

Kosonen, J., Lintu, P., Kortekangas-Savolainen, O., Kalimo, K., Terho, E. O. \& Savolainen, J. (2005). Immediate hypersensitivity to Malassezia furfur and Candida albicans mannans in vivo and in vitro. Allergy 60, 238-242.

Larocco, M., Dorenbaum, A., Robinson, A. \& Pickering, L. K. (1988). Recovery of Malassezia pachydermatis from eight infants in a neonatal intensive care nursery: clinical and laboratory features. Pediatr Infect Dis J 7, 398-401.

Latgé, J. P., Kobayashi, H., Debeaupuis, J. P., Diaquin, M., Sarfati, J., Wieruszeski, J. M., Parra, E., Bouchara, J. P. \& Fournet, B. (1994). Chemical and immunological characterization of the extracellular galactomannan of Aspergillus fumigatus. Infect Immun 62, 5424-5433.

Lengeler, K. B., Tielker, D. \& Ernst, J. F. (2008). Protein-Omannosyltransferases in virulence and development. Cell Mol Life Sci 65, 528-544.

Levery, S. B., Toledo, M. S., Suzuki, E., Salyan, M. E., Hakomori, S., Straus, A. H. \& Takahashi, H. K. (1996). Structural characterization of a new galactofuranose-containing glycolipid antigen of Paracoccidioides brasiliensis. Biochem Biophys Res Commun 222, 639-645.

Lintu, P., Savolainen, J., Kalimo, K., Savolainen, O. K., Nermes, M. \& Terho, E. O. (1999). Cross-reacting $\operatorname{IgE}$ and $\operatorname{IgG}$ antibodies to 
Pityrosporum ovale mannan and other yeasts in atopic dermatitis. Allergy 54, 1067-1073.

Marcon, M. J. \& Powell, D. A. (1992). Human infections due to Malassezia spp. Clin Microbiol Rev 5, 101-119.

Mathov, I., Plotkin, L., Abatangelo, C., Galimberti, R., Squiquera, L. \& Leoni, J. (1996). Antibodies from patients with psoriasis recognize $\mathrm{N}$ acetylglucosamine terminals in glycoproteins from Pityrosporum ovale. Clin Exp Immunol 105, 79-83.

Matsumoto, M., Tanaka, T., Kaisho, T., Sanjo, H., Copeland, N. G., Gilbert, D. J., Jenkins, N. A. \& Akira, S. (1999). A novel LPS-inducible C-type lectin is a transcriptional target of NF-IL6 in macrophages. J Immunol 163, 5039-5048.

Mittag, H. (1995). Fine structural investigation of Malassezia furfur. II. The envelope of the yeast cells. Mycoses 38, 13-21.

Notermans, S., Veeneman, G. H., van Zuylen, C. W., Hoogerhout, P. \& van Boom, J. H. (1988). $(1 \rightarrow 5)$-linked $\beta$-D-galactofuranosides are immunodominant in extracellular polysaccharides of Penicillium and Aspergillus species. Mol Immunol 25, 975-979.

Pan, F., Jackson, M., Ma, Y. \& McNeil, M. (2001). Cell wall core galactofuran synthesis is essential for growth of mycobacteria. J Bacteriol 183, 3991-3998.

Shibata, N., Ikuta, K., Imai, T., Satoh, Y., Satoh, R., Suzuki, A., Kojima, C., Kobayashi, H., Hisamichi, K. \& Suzuki, S. (1995). Existence of branched side chains in the cell wall mannan of pathogenic yeast, Candida albicans. Structure-antigenicity relationship between the cell wall mannans of Candida albicans and Candida parapsilosis. J Biol Chem 270, 1113-1122.

Shibata, N., Suzuki, A., Kobayashi, H. \& Okawa, Y. (2007). Chemical structure of the cell-wall mannan of Candida albicans serotype A and its difference in yeast and hyphal forms. Biochem $J$ 404, 365372.

Sugita, T., Tajima, M., Takashima, M., Amaya, M., Saito, M., Tsuboi, R. \& Nishikawa, A. (2004). A new yeast, Malassezia yamatoensis, isolated from a patient with seborrheic dermatitis, and its distribution in patients and healthy subjects. Microbiol Immunol 48, 579-583.

Suzuki, S. \& Takeda, N. (1977). Immunochemical studies on the galactomannans isolated from mycelia and culture broths of three Hormodendrum strains. Infect Immun 17, 483-490.

Tsuji, S., Uehori, J., Matsumoto, M., Suzuki, Y., Matsuhisa, A., Toyoshima, K. \& Seya, T. (2001). Human intelectin is a novel soluble lectin that recognizes galactofuranose in carbohydrate chains of bacterial cell wall. J Biol Chem 276, 23456-23463.

Welbel, S. F., McNeil, M. M., Pramanik, A., Silberman, R., Oberle, A. D., Midgley, G., Crow, S. \& Jarvis, W. R. (1994). Nosocomial Malassezia pachydermatis bloodstream infections in a neonatal intensive care unit. Pediatr Infect Dis J 13, 104-108.

Wieneke, R., Klein, S., Geyer, A. \& Loos, E. (2007). Structural and functional characterization of galactooligosaccharides in Nostoc commune: $\quad \beta$-D-galactofuranosyl- $(1 \rightarrow 6)-[\beta \text {-D-galactofuranosyl- }(1 \rightarrow 6)]_{2}-\beta$ D-1,4-anhydrogalactitol and $\beta$-(1 $\rightarrow 6)$-galactofuranosylated homologues. Carbohydr Res 342, 2757-2765.

Willment, J. A. \& Brown, G. D. (2008). C-type lectin receptors in antifungal immunity. Trends Microbiol 16, 27-32.

Yamasaki, S., Matsumoto, M., Takeuchi, O., Matsuzawa, T., Ishikawa, E., Sakuma, M., Tateno, H., Uno, J., Hirabayashi, J. \& other authors (2009). C-type lectin Mincle is an activating receptor for pathogenic fungus, Malassezia. Proc Natl Acad Sci U S A 106, 1897-1902.

Edited by: Joachim F. Ernst 